\title{
Evaluation of the prognostic utility of the combination of platelet count with mean platelet volume as a prognostic indicator in head and neck cancer
}

\author{
TRISTAN THAM, EDRIC LEUNG, CAITLIN OLSON, MICHAEL WOTMAN, JULIAN KHAYMOVICH, \\ JOSEPHINE COURY, SIREESHA TEEGALA and PETER COSTANTINO \\ Department of Otolaryngology - Head and Neck Surgery, Zucker School of Medicine at Hofstra/Northwell, \\ New York Head \& Neck Institute, New York, NY 10075, USA
}

Received July 18, 2018; Accepted January 24, 2019

DOI: $10.3892 /$ mco.2019.1813

\begin{abstract}
The combination of platelet count to mean platelet volume (COP-MPV) has been recently reported as a prognostic indicator of oral cavity cancer and other cancer sites. The aim of the present study was to validate the utility of the COP-MPV as a prognostic indicator in all head and neck cancer (HNC) sites. The clinicopathological characteristics of the COP-MPV with HNC were also investigated. This is a retrospective cohort study that recruited consecutively treated patients at a tertiary level academic hospital. Clinicopathological characteristics were recorded, including the COP-MPV scores. Survival was analyzed using Kaplan-Meier analysis, as well as multivariate Cox Proportional Hazards regression. COP-MPV was not associated with the survival outcome in univariate or multivariate analysis. In the multivariate model, tumor differentiation, tumor stage, nodal stage, surgical margins and hemoglobin were revealed to be significantly associated with survival. The results demonstrated that the COP-MPV is not a suitable prognostic factor for HNC.
\end{abstract}

\section{Introduction}

Head and neck cancers (HNC) account for a significant proportion of cancers in the USA (1). HNCs are typically treated with surgery, radiotherapy, chemotherapy, or in combination. Single surgical treatment with or without radiation is the standard therapy for Tumor-Node-Metastases (TNM) stages I and II (2). On the other hand, a combination of surgery, radiotherapy, and chemotherapy may be used for more advanced TNM stages (3). TNM staging is a widely used scoring

Correspondence to: Dr Tristan Tham, Department of Otolaryngology - Head and Neck Surgery, Zucker School of Medicine at Hofstra/Northwell, New York Head \& Neck Institute, 130 East 77th Street, New York, NY 10075, USA

E-mail: ttham@northwell.edu

Key words: head and neck cancer, platelet count, mean platelet volume, head and neck surgery system among prognostic factors for determining patient survival $(1,4)$. Previously, several biomarkers were studied as serologic markers albeit low specificity and difficult clinical application (5). As such, there is a need for finding effective and clinically efficient biomarkers purposed as prognostic factors for $\mathrm{HNCs}$ (6-8).

In recent studies, platelet activation was observed to be a significant biological process for cancer occurrence and metastasis (9). Platelet (PLT) and mean platelet volume (MPV) are typical measures of platelet activation (10), where high levels of MPV signify irregular platelet production and activation (11). It has also been observed that abnormal MPV levels are associated with patients with various disorders and malignant tumors. Building on this information, several studies have recently investigated the prognostic utility of the combination of PLT and MPV (COP-MPV). A recent study by Park et al (12) found that the COP-MPV was a significant prognostic indicator in oral cavity cancer. Additionally, the COP-MPV has been found to be a prognostic indicator in non-small cell lung cancer (NSCLC) (13), and esophageal cancer as well (14). The study by Park was a small sample study with only 40 patients, and only consisted of patients with oral cavity cancer (12). In this context, the goal of our study was to (a) evaluate the prognostic utility of the COP-MPV in a larger sample size, with patients of all HNC subsites and (b) to determine the clinicopathological characteristics associated with COP-MPV.

\section{Materials and methods}

Study design. This is a retrospective cohort study that included consecutively-treated patients with HNC treated at the New York Head \& Neck Institute (NYHNI) from 2009-2016. This study is part of a large retrospectively managed cancer database $(15,16)$ and was approved by the Institutional Review Board of the Northwell Health System (IRB\# 17-0280-LHH). The study conforms to the guidelines stupilated in the Declaration of Helsinki. The inclusion criteria of the study included: i) histologically confirmed HNC (excluding thyroid); ii) undergoing curative intent surgery; iii) availability of complete clinical data and disease records. The exclusion criteria included: i) clinical evidence of pretreatment infection, other inflammatory disease 
or comorbidity that would influence results of the platelet count; ii) benign disease; iii) biopsies or non-curative intent procedures or palliative procedures; iv) lymphoproliferative malignancies; v) incomplete medical records which include absence of preoperative complete blood count (CBC); vi) CBC that was taken more than two weeks pre-operatively; and vii) neoadjuvant chemotherapy or radiation therapy. Patients were screened with pre-defined International Classification of Diseases (ICD) 9/10 codes and were treated according to physician discretion consistent with contemporary treatment paradigms.

Variable selection and data collection. Various literature were reviewed for significant prognostic factors in $\mathrm{HNC}$ that could be used to generate univariate and multivariate statistical models. The established prognostic factors for HNC used in the data collection process included: age, sex, body mass index (BMI), alcohol history, smoking history, eastern cooperative oncology group (ECOG) score, and Karnofsky performance status. All patients were retrospectively graded based on the Adult Comorbidity Evaluation 27 (ACE-27) score, a validated comorbidity scoring system for head and neck cancer (17). Treatment and tumor variables were also incorporated: Tumor differentiation, staging (8th Edition of American Joint Committee on Cancer System) (18), adjuvant radiation (RT), adjuvant chemotherapy (CT), and surgical margin status. For oropharyngeal tumors, human papillomavirus (HPV) status was determined according to either p16 positivity via immunohistochemistry, or HPV DNA detection. In addition, CBC markers of interest were considered as well and included: the hemoglobin $(\mathrm{Hb})$, platelet count, mean platelet volume, and white blood cell count (WBC). Since a unified scoring system has not been developed for the COP-MPV, we utilized the scoring system developed in the largest dataset published on the COP-MPV, by Zhang et al (14). The cutoffs for platelet count and platelet volume were set to $212\left(10^{9} / \mathrm{L}\right)$ and 10.6 (fl) respectively. A score of 1 was given if one of the cutoffs were met, and a score of 2 was given if both cutoffs were met.

Patient records were retrieved electronically from the REDCap database (19). Necessary and relevant clinical information were gathered from the patients' scanned documents. Such documents included clinical, pathological, or laboratory reports. CBC parameters were obtained from preoperative lab results.

Endpoint definition. Event-free survival (EFS) was chosen as the primary endpoint. We chose EFS as the primary endpoint as a recent study by Michiels et al (20) had shown that the EFS was an effective proxy for OS as the primary survival endpoint. EFS was defined as the date of surgery to last follow-up or 'event', depending on which date was earliest. An 'event' was defined as any progress, local or distant recurrence, or death. If there was no occurrence of an 'event' at the last follow-up, the patient was censored for the survival analysis.

Statistical analysis. Parametric tests such as Chi-square tests and t-tests were used to evaluate the differences between the relationship of clinicopathological features. With Kaplan-Meier curves (KM), EFS was estimated and log-rank tests were used to identify survival differences between the KM curves. Furthermore, Cox proportional hazards model $(\mathrm{CPH})$ was used to determine the hazard ratio (HR) of the aforementioned variables. Multivariate analyses was conducted on all variables recorded with regards to EFS. For generating a multivariate $\mathrm{CPH}$ model, backwards variable selection was used. For the backwards multivariate model, variables with $\mathrm{P}>0.1$ were removed from the model. Hazard ratios (HR) with $95 \%$ confidence intervals $(95 \% \mathrm{CI})$ with two-sided P-values are presented. The chosen alpha level was 0.05 , and all P-values less than the alpha level were considered statistically significant. All statistical analyses, excluding cutoff derivation, were performed using MedCalc for Windows, version 15.0 (MedCalc Software bvba, Ostend, Belgium).

\section{Results}

A total of 113 patients met the inclusion and exclusion criteria for this study (Table I). The most common site of tumor was the Oral Cavity (46\%) followed by the oropharynx (18\%). Of the oropharyngeal tumors, $15(75 \%)$ were associated with either p16 or HPV DNA. In regards to tumor histology, the most prominent type was squamous cell carcinoma (93 patients, $82.3 \%)$. A total of 27 (24\%) patients had a COP-MPV score of $0,65(58 \%)$ of patients had score of 1 , and $21(19 \%)$ of patients had score of 2. With regards to the clinicopathological characteristics and COP-MPV score, only WBC count was associated with higher COP-MPV values $(\mathrm{P}=0.0036$, Table I).

With regards to the survival analysis, the multivariate analysis of EFS revealed that age, sex, BMI, Karnofsky score, ACE score, tumor differentiation, Staging-N, WBC, platelet count, and COP MPV were not significant prognostic indicators (Table II). The factors associated with EFS in the multivariable model were higher tumor grade $(\mathrm{HR}=2.37$, 95\% CI: 1.17-4.84, $\mathrm{P}=0.0171)$, higher tumor stage $(\mathrm{HR}=8.91$, 95\% CI: $3.46-22.91, \mathrm{P}<0.0001)$, higher nodal stage ( $\mathrm{pN} 1$ HR=3.41,95\% CI: $1.11-10.47, \mathrm{P}=0.0321$; $\mathrm{pN} 2 \mathrm{HR}=3.30,95 \% \mathrm{CI}$ 1.23-8.86, $\mathrm{P}=0.0177)$, positive surgical margins $(\mathrm{HR}=3.77$, 95\% CI: 1.54-9.24, $\mathrm{P}=0.0037$ ), and higher hemoglobin count (HR=0.62, 95\% CI: 0.50-0.78, P<0.0001). COP-MPV was not associated with EFS in the multivariate survival analysis. To confirm if COP-MPV did not have a prognostic effect, we performed a further Kaplan Meier analysis with a log-rank test. The Kaplan-Meier analysis revealed that COP-MPV was not associated with EFS ( $\mathrm{P}=0.3723$, Fig. 1).

\section{Discussion}

The COP-MPV scoring system was developed by combining PLT and MPV to measure platelet activation and to assess the prognosis of cancer patients. As such, previous studies revealed COP-MPV to be an ideal and effective prognostic factor for these type of patients (12-14). Building upon previous research by others, this study sought to validate the prognostic value of COP-MPV for all HNC subsites. The results and analyses of this study revealed that COP-MPV was not associated with our primary survival outcome, EFS. There were no significant differences between COP-MPV scores of 0,1 and 2 with regard to EFS. Additionally, COP-MPV was not associated with EFS in the univariate Kaplan Meier analysis either. In our multivariate survival analysis, we found that known factors for survival, namely differentiation, tumor stage, surgical margins, and hemoglobin were associated with EFS. 
Table I. Summary of cohort characteristics stratified by COP-MPV.

\begin{tabular}{|c|c|c|c|c|}
\hline Variable & COP-MPV $0^{\mathrm{a}}$ & COP-MPV $1^{\mathrm{a}}$ & COP-MPV $2^{\mathrm{a}}$ & P-value \\
\hline Age (years) & 66.48 & 63.23 & 64.048 & 0.6027 \\
\hline \multicolumn{5}{|l|}{ Sex } \\
\hline Male & 20 & 43 & 13 & \multirow[t]{2}{*}{0.6444} \\
\hline Female & 7 & 22 & 8 & \\
\hline BMI $\left(\mathrm{kg} / \mathrm{m}^{2}\right)$ & 24.89 & 26.50 & 28.76 & 0.0655 \\
\hline \multicolumn{5}{|l|}{ History of alcohol use } \\
\hline Yes & 12 & 33 & 12 & \multirow[t]{2}{*}{0.6810} \\
\hline No & 15 & 32 & 9 & \\
\hline \multicolumn{5}{|l|}{ History of smoking } \\
\hline Yes & 13 & 31 & 12 & \multirow[t]{2}{*}{0.7426} \\
\hline No & 14 & 34 & 9 & \\
\hline \multicolumn{5}{|l|}{ ECOG score } \\
\hline 0 & 16 & 50 & 16 & \multirow[t]{3}{*}{0.3801} \\
\hline 1 & 9 & 14 & 4 & \\
\hline 2 & 2 & 1 & 1 & \\
\hline \multicolumn{5}{|l|}{ Tumor primary location } \\
\hline Nasopharynx & 0 & 1 & 0 & \multirow[t]{8}{*}{0.2692} \\
\hline Oropharynx & 5 & 13 & 2 & \\
\hline Oral cavity & 8 & 29 & 15 & \\
\hline Larynx & 4 & 6 & 0 & \\
\hline Salivary gland & 3 & 7 & 2 & \\
\hline Paranasal sinus & 2 & 5 & 0 & \\
\hline Cervical lymph node or unknown primary & 2 & 1 & & \\
\hline Cutaneous & 3 & 3 & 0 & \\
\hline \multicolumn{5}{|l|}{ Tumor histology } \\
\hline Adenocarcinoma & 1 & 5 & 0 & \multirow[t]{6}{*}{0.6290} \\
\hline Squamous cell carcinoma & 21 & 52 & 20 & \\
\hline Adenoid cystic carcinoma & 1 & 1 & 0 & \\
\hline Mucoepidermoid carcinoma & 1 & 1 & 0 & \\
\hline Basal cell carcinoma & 1 & 0 & 0 & \\
\hline Other & 2 & 6 & 1 & \\
\hline \multicolumn{5}{|l|}{ Tumor differentiation } \\
\hline Unable to assess & 7 & 5 & 4 & \multirow[t]{4}{*}{0.0617} \\
\hline Well differentiated & 7 & 10 & 3 & \\
\hline Moderate differentiation & 11 & 29 & 10 & \\
\hline Poor differentiation & 2 & 21 & 4 & \\
\hline \multicolumn{5}{|l|}{ Staging pT } \\
\hline pT0 & 2 & 2 & 2 & \multirow[t]{5}{*}{0.6384} \\
\hline $\mathrm{pT} 1$ & 10 & 25 & 9 & \\
\hline pT2 & 11 & 19 & 6 & \\
\hline pT3 & 3 & 11 & 1 & \\
\hline pT4 & 1 & 8 & 3 & \\
\hline \multicolumn{5}{|l|}{ Staging pN } \\
\hline pN0 & 19 & 41 & 16 & \multirow[t]{4}{*}{0.8009} \\
\hline $\mathrm{pN} 1$ & 3 & 10 & 2 & \\
\hline $\mathrm{pN} 2$ & 3 & 7 & 3 & \\
\hline $\mathrm{pN} 3$ & 2 & 6 & 0 & \\
\hline \multicolumn{5}{|l|}{ Adjuvant radiotherapy } \\
\hline Yes & 12 & 27 & 4 & \multirow[t]{2}{*}{0.1339} \\
\hline No & 15 & 38 & 17 & \\
\hline
\end{tabular}


Table I. Continued.

\begin{tabular}{|c|c|c|c|c|}
\hline Variable & COP-MPV $0^{a}$ & COP-MPV $1^{\mathrm{a}}$ & COP-MPV $2^{\mathrm{a}}$ & P-value \\
\hline \multicolumn{5}{|c|}{ Adjuvant chemoradiotherapy } \\
\hline Yes & 6 & 14 & 2 & 0.4420 \\
\hline No & 21 & 51 & 19 & \\
\hline \multicolumn{5}{|l|}{ Surgical margin status } \\
\hline Positive & 3 & 9 & 3 & 0.9292 \\
\hline Negative & 24 & 56 & 18 & \\
\hline WBC $\left(10^{9} / 1\right)$ & 6.51 & 7.56 & 9.16 & $0.0036^{\mathrm{b}}$ \\
\hline Hemoglobin (g/dl) & 13.39 & 13.30 & 6.81 & 0.1356 \\
\hline MPV (fl) & 9.66 & 9.81 & 11.25 & $<0.0001^{\mathrm{b}}$ \\
\hline Platelet Count $\left(10^{9} / 1\right)$ & 178.33 & 249.88 & 275.14 & $<0.0001^{\mathrm{b}}$ \\
\hline
\end{tabular}

${ }^{\mathrm{a} C}$ Continuous variables presented as mean values and categorical variables are represented as integers; ${ }^{\mathrm{b}}$ Statistically significant at $\mathrm{P}<0.05$. BMI, body-mass index; ACE-27, adult comorbidity evaluation 27 score; ECOG, Eastern Cooperative Oncology Group score; WBC, white blood cell count; MPV, mean platelet volume; COP-MPV, combination of platelet count and mean platelet volume score.

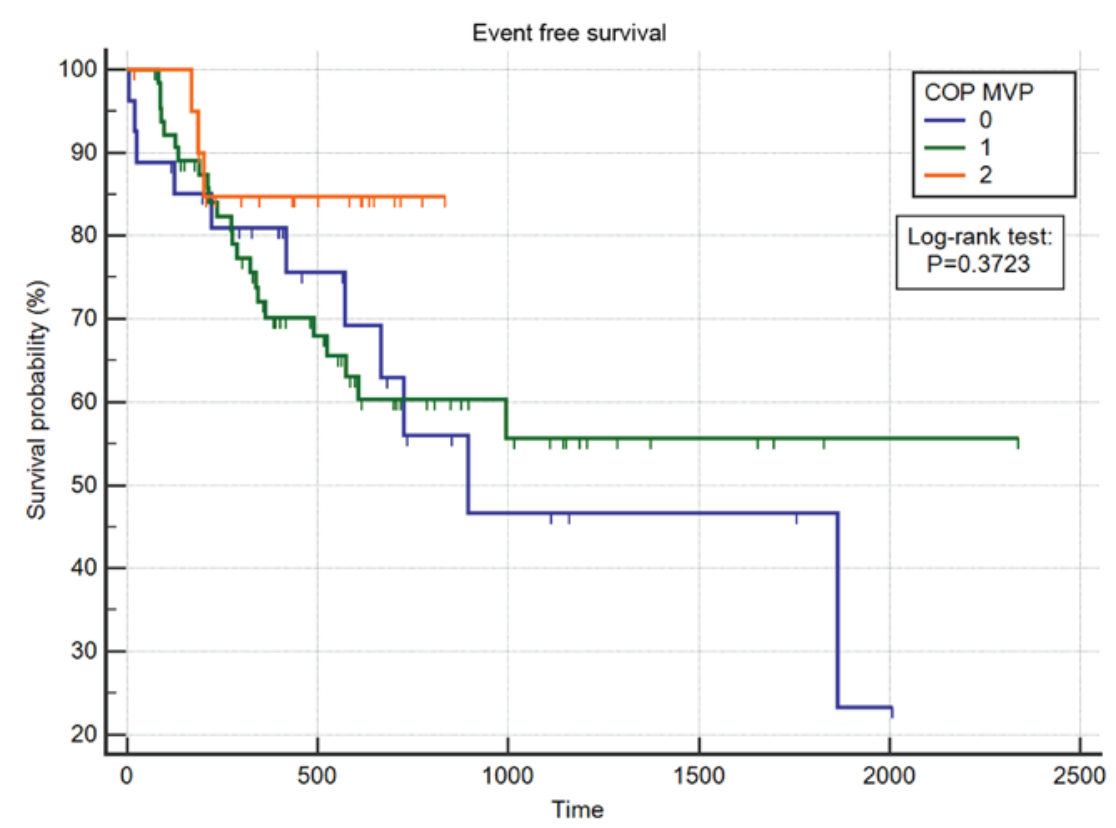

Figure 1. Kaplan Meier curve of the event-free survival of COP-MPV. Kaplan-Meier curve analysis of the event-free survival of the COP-MPV. The log-rank test showed no significant differences between curves ( $\mathrm{P}=0.3723$ ). COP-MPV, combination of platelet count and mean platelet volume.

In comparison to other studies (12-14), similar factors were incorporated into the analyses of the results. This included age, sex, tumor location, degree of differentiation, TNM stage, WBC, platelet count, and mean platelet volume. In this study, we additionally controlled for BMI, ECOG score, Karnofsky score, types of treatment modalities, and surgical margin status.

It should be noted that by accounting for different factors in analyses potential differences in significance values will arise and thus could also influence the determination of whether COP-MPV affects survival. Another key difference between our study and other studies is the area of interest for cancers. In our study various locations of cancer of the head and neck area were included, whereas other studies mainly focused on areas of higher specification or a particular type of carcinom (12-14).
As a result, by considering different afflicted locations it may explain why our significance scores were different from other studies.

Of note, the study by Park et al (12) found that the COP-MPV was significantly associated with survival in their multivariate analysis. However, we believe that their results might be limited due to several reasons. Firstly, they had a small sample size of patients; secondly, their multivariate model did not account for important covariates such as adjuvant therapies and comorbidities which would have significantly biased their results. Our results agree with certain aspects of their study; they also found that tumor stage $(\mathrm{P}=0.735)$ and nodal stage $(\mathrm{P}=1.00)$ were not associated with COP-MPV scores. Nevertheless, we believe the work by Park et al (12) is the 
Table II. Multivariate Cox Regression Analysis of Event-Free Survival.

\begin{tabular}{|c|c|c|c|}
\hline \multirow[b]{2}{*}{ Variable } & \multicolumn{3}{|c|}{ Multivariate analysis } \\
\hline & HR & $95 \%$ CI & P-value \\
\hline Age & $\mathrm{Ns}^{\mathrm{a}}$ & - & - \\
\hline \multicolumn{4}{|l|}{ Sex } \\
\hline Male & Reference & & \\
\hline Female & $\mathrm{Ns}^{\mathrm{a}}$ & - & - \\
\hline BMI & $\mathrm{Ns}^{\mathrm{a}}$ & - & - \\
\hline History of alcohol use & $\mathrm{Ns}^{\mathrm{a}}$ & - & - \\
\hline History of smoking & $\mathrm{Ns}^{\mathrm{a}}$ & - & - \\
\hline Overall ACE-27 score & $\mathrm{Ns}^{\mathrm{a}}$ & - & - \\
\hline ECOG score & $\mathrm{Ns}^{\mathrm{a}}$ & - & - \\
\hline \multicolumn{4}{|l|}{ Karnofsky score } \\
\hline 100 & Reference & & \\
\hline 90 & $\mathrm{Ns}^{\mathrm{a}}$ & - & - \\
\hline 80 & $\mathrm{Ns}^{\mathrm{a}}$ & - & - \\
\hline$\leq 70$ & $\mathrm{c}$ & - & - \\
\hline Tumor primary location & $\mathrm{Ns}^{\mathrm{a}}$ & - & - \\
\hline \multicolumn{4}{|l|}{ Tumor differentiation } \\
\hline Well differentiated & Reference & & \\
\hline $\begin{array}{l}\text { Moderately } \\
\text { differentiated }\end{array}$ & 2.37 & $1.17-4.84$ & $0.0171^{\mathrm{b}}$ \\
\hline Poorly differentiated & $\mathrm{Ns}^{\mathrm{a}}$ & - & - \\
\hline \multicolumn{4}{|l|}{ Staging pT } \\
\hline pT1 & Reference & & \\
\hline pT2 & $\mathrm{Ns}^{\mathrm{a}}$ & - & - \\
\hline pT3 & 8.91 & $3.46-22.91$ & $<0.0001^{\mathrm{b}}$ \\
\hline pT4 & $\mathrm{Ns}^{\mathrm{a}}$ & - & - \\
\hline \multicolumn{4}{|l|}{ Staging $\mathrm{pN}$} \\
\hline pNO & Reference & & \\
\hline $\mathrm{pN} 1$ & 3.41 & $1.11-10.47$ & $0.0321^{\mathrm{b}}$ \\
\hline $\mathrm{pN} 2$ & 3.30 & $1.23-8.86$ & $0.0177^{b}$ \\
\hline $\mathrm{pN} 3$ & $\mathrm{c}$ & & \\
\hline Adjuvant radiotherapy & $\mathrm{Ns}^{\mathrm{a}}$ & - & - \\
\hline $\begin{array}{l}\text { Adjuvant } \\
\text { chemoradiotherapy }\end{array}$ & $\mathrm{Ns}^{\mathrm{a}}$ & - & - \\
\hline Surgical margin status & 3.77 & $1.54-9.24$ & $0.0037^{\mathrm{b}}$ \\
\hline WBC & $\mathrm{Ns}^{\mathrm{a}}$ & - & - \\
\hline Hemoglobin & 0.62 & $0.50-0.78$ & $<0.0001^{\mathrm{b}}$ \\
\hline MPV & 2.16 & $0.95-4.92$ & 0.0659 \\
\hline Platelet count & $\mathrm{Ns}^{\mathrm{a}}$ & - & - \\
\hline \multicolumn{4}{|l|}{ COP-MPV } \\
\hline 0 & Reference & & \\
\hline 1 & $\mathrm{Ns}^{\mathrm{a}}$ & - & - \\
\hline 2 & $\mathrm{Ns}^{\mathrm{a}}$ & - & - \\
\hline
\end{tabular}

${ }^{\mathrm{a}} \mathrm{P}>0.1$, thus these were removed from the multivariate regression model via backwards selection; ${ }^{b}$ Statistically significant $(\mathrm{P}<0.05)$;

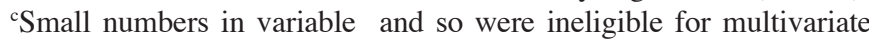
model analysis. 95\% CI, 95\% confidence interval; HR, hazard ratio; BMI, body-mass index; ACE-27, adult comorbidity evaluation 27 score; ECOG, eastern cooperative oncology group score; WBC, white blood cell count; MPV, mean platelet volume; COP-MPV, combination of platelet count and mean platelet volume score; Ns, not significant. first report of COP-MPV for a HNC subsite. In our study, we analyzed patients from all HNC subsites, in a larger sample size than the previous study by Park et al (12).

We acknowledge several limitations in our study. Firstly, this is a retrospective cohort study where some elements of bias might be in the data. Secondly, considering that different types of HNCs were included, each may have their own prognostic characteristics. We are unable to definitely draw a conclusion that the COP-MPV is not effective in all HNC subsites. Our study has several strengths: First, this includes rigorous control for all prognostic covariates in our analyses; Secondly, the included patients had similar treatment regimens where all experienced curative intent surgery with or without adjuvant radiation or chemotherapy; Third, unlike previously mentioned literature, we used the latest staging system (AJCC 8th edition) in our study, which has been shown to have improved prognostic discrimination between stages (18). It should be acknowledged that the use of older staging criteria by other studies might have affected their results. Most importantly, this study adds on to the literature for COP-MPV as this is the first comprehensive study examining the prognostic utility of COP-MPV in all HNC subsites.

In conclusion, we did not find COP-MPV to be related to the survival endpoint EFS. However, high quality prospective studies should be considered and are needed to validate our conclusions for COP-MPV. At this time, we cannot recommend the COP-MPV as a prognostic indicator in HNC.

\section{Acknowledgements}

Not applicable.

\section{Funding}

No funding was received.

\section{Availability of data and materials}

The analyzed data sets generated during the study are available from the corresponding author on reasonable request.

\section{Authors' contributions}

TT, EL, CO, MW, JK, JC, ST and PC conceived and designed the experiments. TT, EL, CO, MW, JK, JC, ST and PC performed the experiments. TT, EL, CO, MW, JK, JC, ST and $\mathrm{PC}$ wrote the paper.

\section{Ethics approval and consent to participate}

The present study was approved by the review boards of the Northwell Health System (New York, NY, USA).

\section{Patient consent for publication}

Not applicable.

\section{Competing interests}

The authors declare that they have no competing interests. 


\section{References}

1. Forastiere A, Koch W, Trotti A and Sidransky D: Head and neck cancer. N Engl J Med 345: 1890-1900, 2001.

2. Lydiatt DD, Robbins KT, Byers RM and Wolf PF: Treatment of stage I and II oral tongue cancer. Head Neck 15: 308-312, 1993.

3. Layland MK, Sessions DG and Lenox J: The influence of lymph node metastasis in the treatment of squamous cell carcinoma of the oral cavity, oropharynx, larynx, and hypopharynx: N0 versus $\mathrm{N}^{+}$. Laryngoscope 115: 629-639, 2005.

4. Woolgar JA, Rogers S, West CR, Errington RD, Brown JS and Vaughan ED: Survival and patterns of recurrence in 200 oral cancer patients treated by radical surgery and neck dissection. Oral Oncol 35: 257-265, 1999.

5. Yotsukura S and Mamitsuka H: Evaluation of serum-based cancer biomarkers: A brief review from a clinical and computational viewpoint. Crit Rev Oncol Hematol 93: 103-115, 2015.

6. Tham T, Bardash Y,Herman SW and Costantino PD: Neutrophil-tolymphocyte ratio as a prognostic indicator in head and neck cancer: A systematic review and meta-analysis. Head Neck 40: 2546-2557, 2018.

7. Tham T, Olson C, Khaymovich J, Herman SW and Costantino PD: The lymphocyte-to-monocyte ratio as a prognostic indicator in head and neck cancer: A systematic review and meta-analysis. Eur Arch Otorhinolaryngol 275: 1663-1670, 2018.

8. Tham T, Bardash Y, Teegala S, Herman WS and Costantino PD The red cell distribution width as a prognostic indicator in upper aerodigestive tract (UADT) cancer: A systematic review and meta-analysis. Am J Otolaryngol 39: 453-458, 2018.

9. Lip GY, Chin BS and Blann AD: Cancer and the prothrombotic state. Lancet Oncol 3: 27-34, 2002.

10. Kamath S, Blann AD and Lip GY: Platelet activation: Assessment and quantification. Eur Heart J 22: 1561-1571, 2001.

11. Gasparyan AY, Ayvazyan L, Mikhailidis DP and Kitas GD: Mean platelet volume: A link between thrombosis and inflammation? Curr Pharm Des 17: 47-58, 2011.

12. Park JW, Kim CH, Ha YC, Kim MY and Park SM: Count of platelet and mean platelet volume score: Serologic prognostic factor in patients with oral squamous cell carcinoma. J Korean Assoc Oral Maxillofac Surg 43: 305-311, 2017.
13. Gao L, Zhang H, Zhang B, Zhang L and Wang C: Prognostic value of combination of preoperative platelet count and mean platelet volume in patients with resectable non-small cell lung cancer. Oncotarget 8: 15632-15641, 2017.

14. Zhang F, Chen Z, Wang P, Hu X, Gao Y and He J: Combination of platelet count and mean platelet volume (COP-MPV) predicts postoperative prognosis in both resectable early and advanced stage esophageal squamous cell cancer patients. Tumour Biol 37 : 9323-9331, 2016

15. Tham T, Khaymovich $\mathrm{J}$ and Costantino P: Investigation of the relationship between markers of systemic inflammatory response and head and neck tumor characteristics. bioRxiv: Aug 23, 2018 (Epub ahead of print). doi: https://doi.org/10.1101/399162.

16. Tham T, Olson C, Wotman M, Teegala S, Khaymovich J, Coury J and Costantino P: Evaluation of the prognostic utility of the hemoglobin-to-red cell distribution width ratio in head and neck cancer. Eur Arch Otorhinolaryngol 275: 2869-2878, 2018.

17. Piccirillo JF, Tierney RM, Costas I, Grove L and Spitznagel EL Jr: Prognostic importance of comorbidity in a hospital-based cancer registry. JAMA 291: 2441-2447, 2004.

18. Amin MB, Edge SB, Greene FL, Byrd DR, Brookland RK, Washington MK, Gershenwald JE, Compton CC, Hess KR, Sullivan DC, et al (eds): AJCC Cancer Staging Manual. 8th edition. Springer, New York, NY, 2017.

19. Harris PA, Taylor R, Thielke R, Payne J, Gonzalez N and Conde JG: Research electronic data capture (REDCap) - a metadata-driven methodology and workflow process for providing translational research informatics support. J Biomed Inform 42: 377-381, 2009.

20. Michiels S, Le Maître A, Buyse M, Burzykowski T, Maillard E, Bogaerts J, Vermorken JB, Budach W, Pajak TF, Ang KK, et al; $\mathrm{MARCH}$ and MACH-NC Collaborative Groups: Surrogate endpoints for overall survival in locally advanced head and neck cancer: Meta-analyses of individual patient data. Lancet Oncol 10: 341-350, 2009. 